\title{
Forward osmosis (FO)-reverse osmosis (RO) hybrid process incorporated with hollow fiber FO
}

\author{
S.-J. $\operatorname{Im}^{1,2}$, S. Jeong ${ }^{3}$ and A. Jang $\mathbb{1 D}^{1 凶}$
}

Currently, desalination is limited by high energy consumption and high operational and maintenance costs. In this study, a new concept of a hollow fiber forward osmosis (HFFO)-based infinity desalination process with minor environmental impacts (freeenergy intake and no pretreatment or brine discharge) is suggested. To evaluate the concept, an element-scale HFFO was conducted in both conventional FO and pressure-assisted FO modes, simulating a submerged HFFO operation. In the HFFO test, the impacts of several operating conditions on the performance of the HFFO were investigated to select the best case. Based on these results, the energy costs were calculated and compared with those of a hybrid FO-seawater reverse osmosis (SWRO) process. The HFFO showed a high dilution rate of the draw solution (up to approximately 400\%), allowing the downstream SWRO process to operate at 25 bar with the same permeate volume production (recovery rate of $60 \%$ ). Consequently, the HFFO-based infinity desalination process has an annual energy revenue of 183.83 million USD, compared with a stand-alone two-stage RO process based on a $100,000 \mathrm{~m}^{3} /$ day plant.

npj Clean Water (2021)4:51; https://doi.org/10.1038/s41545-021-00143-0

\section{INTRODUCTION}

Because membrane-based desalination processes do not undergo a phase change, they have gained attention as cost-effective techniques compared with thermal-based desalination and require a relatively small footprint ${ }^{1,2}$. These methods produce high-quality water consistently, and the production rates are easily adjustable. However, membrane fouling and high chemical usage and operating costs remain as critical issues ${ }^{3,4}$. Of the membranebased desalination processes currently available, the reverse osmosis (RO) process is a stand-alone process and its market share in seawater desalination is rapidly increasing. However, energy consumption in the seawater reverse osmosis (SWRO) process continues to be a limitation ${ }^{2,5}$.

The current energy cost of the SWRO process is much lower than that of thermal-based desalination processes $\left(15.5 \mathrm{kWh} / \mathrm{m}^{3}\right.$ for multistage flash (MSF) and $7.5 \mathrm{kWh} / \mathrm{m}^{3}$ for multi-effect distillation (MED)). Despite the application of internal stage design technology and the development of an energy-recovery device, SWRO continues to be energy-intensive $\left(2.2-3.5 \mathrm{kWh} / \mathrm{m}^{3}\right)$ process $\mathrm{s}^{6,7}$ as compared to conventional water treatment processes such as membrane-based wastewater treatment $\left(0.29-0.43 \mathrm{kWh} / \mathrm{m}^{3}\right)$ and ozone-based water treatment $\left(0.041-0.073 \mathrm{kWh} / \mathrm{m}^{3}\right)^{8,9}$. Therefore, SWRO-based desalination has reached the theoretical and practical limit, and it is time for process development or grafting to further reduce energy consumption ${ }^{10,11}$. Energy limitation must be overcome through additional technical solutions such as energy harvesting, seawater dilution, and reducing irreversible ${ }^{10,12}$. This high energy usage during desalination causes environmental concerns such as air pollution and heat associated with water cooling using energy production from fossil fuels ${ }^{2,4}$. Several studies have been conducted to solve the energy issue in the SWRO process ${ }^{10,13,14}$. Other membrane processes, such as forward osmosis $(\mathrm{FO})^{15}$, membrane distillation (MD) ${ }^{16}$, and nanofiltration (NF) ${ }^{6}$, have been combined, and seawater has been directly or indirectly mixed with other available water resources to reduce the energy cost of the SWRO process. The SWRO process also has been hybridized with energy production processes, including pressure-retarded osmosis (PRO) ${ }^{17}$, reverse electrodialysis (RED) ${ }^{18}$, and microbial fuel cell $(\mathrm{MFC})^{19}$, to offset the high energy consumption.

Another drawback of SWRO-based desalination is the production of high-salinity brine, which contains corrosive substances, residual pretreatment and posttreatment chemicals, ionic and heavy metals, and salts that are harmful to the environment when discharged directly into the sea ${ }^{5,20}$. The brine can also directly influence the eutrophication and $\mathrm{pH}$ fluctuation in a marine ecosystem. Several studies have suggested solutions to reduce the brine impacts. First, zero liquid discharge (ZLD) technology that recovers $100 \%$ of the water and recycles useful resources in the brine has been applied to minimize the brine discharge (outfall) ${ }^{21}$. In this case, some emerging posttreatment processes have been applied, including FO, PRO, MD, MED, and an ohmic evaporator, to treat high-salinity water, reduce the brine concentration, and maximize the efficiency of chemical precipitation (recovering valuable resources) ${ }^{22-24}$. However, the ZLD technology is too expensive to be used in a full-scale desalination plant ${ }^{25}$.

FO uses differential natural osmotic pressure as a driving force. Based on this principle, the energy consumption required is minimized during the operation ${ }^{26}$. However, the FO process inevitably requires post-processes, such as RO and NF, to obtain the final water production, creating a significant obstacle for its use as a stand-alone desalination process or commercializa$\operatorname{tion}^{27,28}$. If pressurized membrane processes are necessary downstream, it is difficult to say that FO is a stand-alone desalination process and low-energy process ${ }^{29,30}$.

In this regard, the FO-RO hybrid process has recently been suggested as a low-energy and eco-friendly next-generation seawater desalination process to complement the disadvantages of the conventional SWRO process ${ }^{31}$. At the same time,

\footnotetext{
${ }^{1}$ Graduate School of Water Resources, Sungkyunkwan University (SKKU), 2066 Seobu-ro, Jangan-gu, Suwon, Gyeonggi-do 16419, Republic of Korea. ${ }^{2}$ Department of Civil and Environmental Engineering, University of California, Los Angeles, CA 90095-1593, USA. ${ }^{3}$ Environmental Engineering, Pusan National University, Busan 46241, Republic of Korea.

凶email: amjang@skku.edu
} 
wastewater can be reused with this system if a suitable feed solution (FS) is used in the FO process ${ }^{32,33}$.

Still, several functions of the FO-RO hybrid process have substantial operational costs, including the intake, pretreatment, and drainage (or treatment) of the FS and draw solution (DS), creating an economic burden. Brine discharge produces another limitation in both economic and environmental aspects ${ }^{6,27}$. The utilization of the intake, pretreatment, drainage, and brine discharge directly affects both the operational expenditure (OPEX) and capital expenditure (CAPEX) in the desalination plant ${ }^{34}$.

Therefore, this study suggests a new hybrid process, FO-RO with a hollow fiber FO (HFFO), to complement the limitations of the FO-RO hybrid process. This new configuration (FO-RO-sHFFO (submerged HFFO)) has a distinct sequence and several advantages. First, the seawater (DS of the first FO) is diluted through the sHFFO process (the second FO) and is reconcentrated through the $\mathrm{RO}$ process, which can be operated at lower pressure or generate a higher recovery rate than the original SWRO, producing clean water simultaneously. Subsequently, the concentrated seawater (brine) generated from the RO process is diluted with the seawater through the sHFFO process and directly recycled as the DS for the first FO process. As a result, in the sHFFO-incorporated FO-RO desalination process, the seawater can be fed without any intake pump or pretreatment. In addition, a brine discharge system is not required because brine is used as a driving force for the sHFFO process. The operating pressure of the downstream RO process can be reduced because the diluted seawater from the HFFO process is used, and the FS is further diluted by the wastewater from the first FO process, reducing energy consumption. Furthermore, the circulating energy (or pressure) for the DS in the sHFFO process can be utilized as the residual pressure of the brine after recovery using an energy-recovery device applied to the RO process. The FS for the sHFFO process does not require a circulating pump because natural seawater is used as the FS. The sHFFO process can be operated at different water levels, which makes the FO operation more flexible. In other words, it can be operated with an applied pressure generated by the water level, referred to as pressure-assisted $\mathrm{FO}(\mathrm{PAO})^{35}$. This process helps make the FO operation changeable according to the RO recovery rate and enables natural physical cleaning owing to the difference in osmosis levels.

In this study, an HFFO module was operated at different FS and DS concentrations and flow rates. In the PAO mode, the applied pressures affecting the process performance were varied. In addition, the feasibility and applicability of this process were assessed through an energy cost evaluation and compared with the FO-RO hybrid process and two-stage RO with the ZLD system.

\section{RESULTS}

\section{HFFO performance evaluation}

Figure 1 shows the water flux and reverse salt flux (RSF) values of the HFFO element tested at varying (i) operating modes ( $a$ and $b$ : FO; $c$ and d: PAO), (ii) flow rates of the FS and DS, and (iii) DS concentrations. The results showed that the flow rate of each side influenced the performance of the element-scale HFFO (Fig. 1a, b). When the DS flow rate was increased from 0.20 to $0.35 \mathrm{~L} / \mathrm{min}$ with different FS flow rates $(0.7,1.0$, and $1.5 \mathrm{~L} / \mathrm{min})$, the overall water flux increased (maximum: $35,000 \mathrm{mg} / \mathrm{L}-1.05$ to 1.24 liter per square meter per hour (LMH), minimum: $0.95-1.08 \mathrm{LMH}$ at high DS concentration condition) (maximum: $35,000 \mathrm{mg} / \mathrm{L}-0.83$ to 1.24 $\mathrm{LMH}$ at high DS concentration condition, minimum: $0.46-0.60$ a)

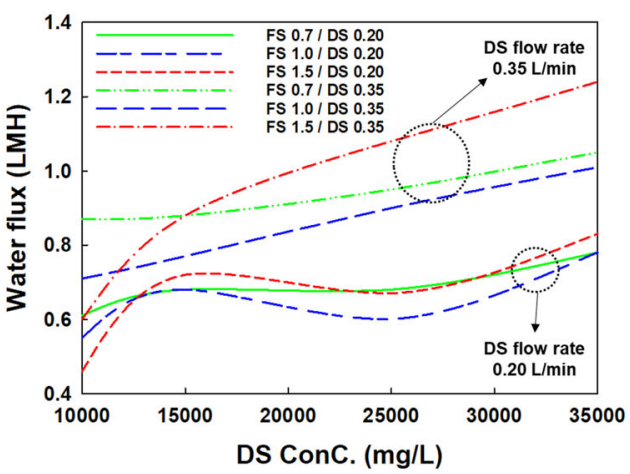

c)

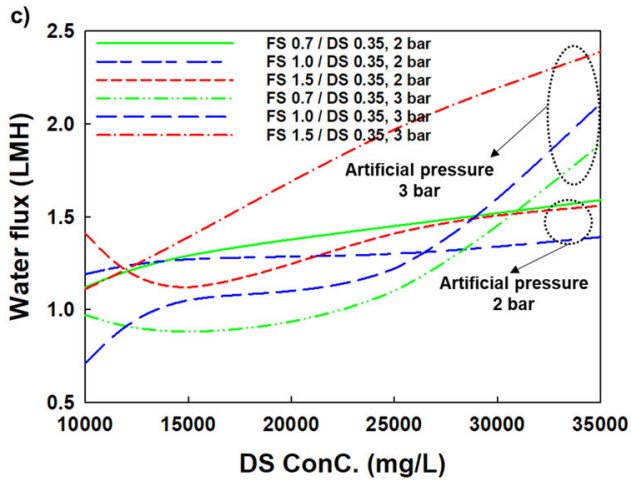

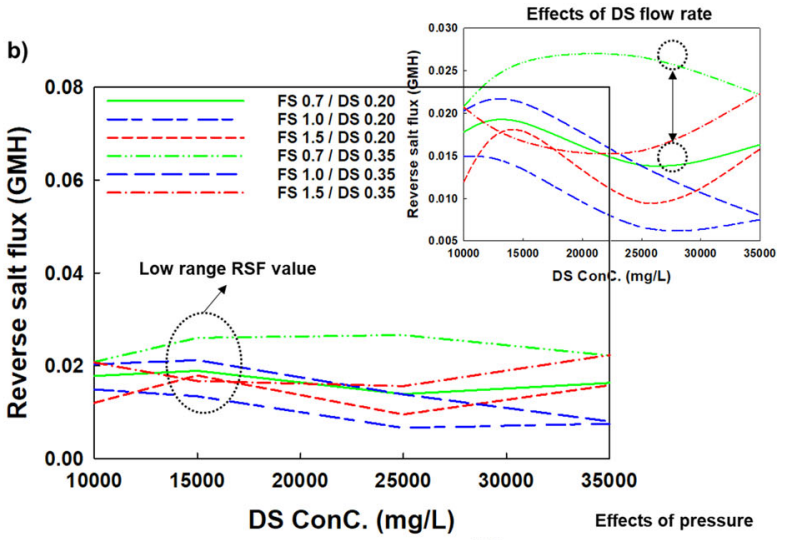

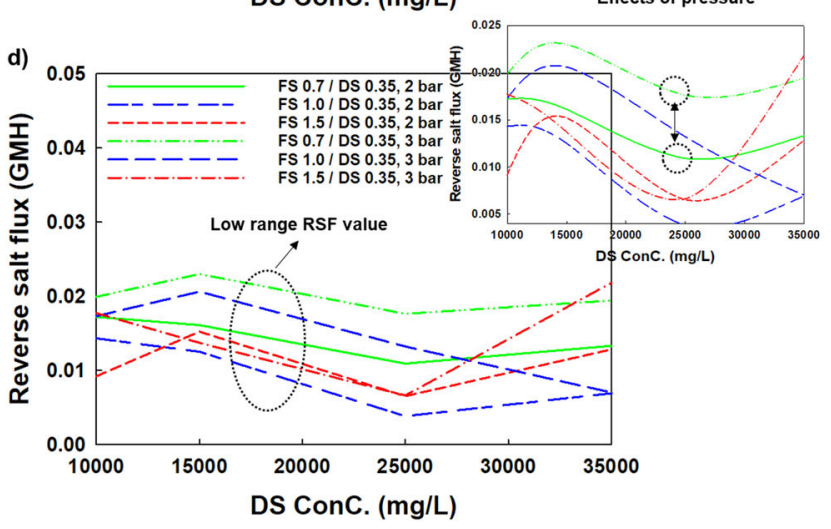

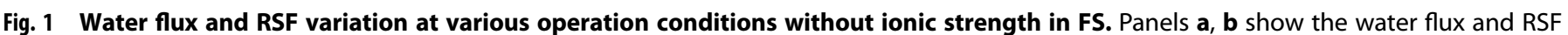

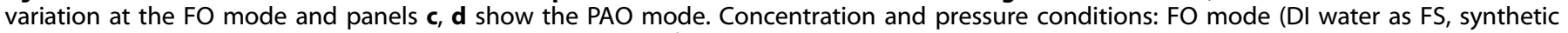

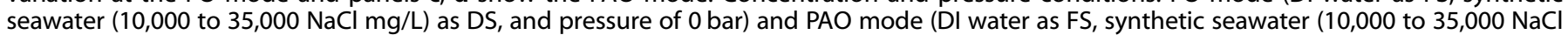

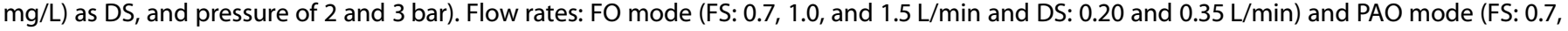
1.0, and $1.5 \mathrm{~L} / \mathrm{min}$ and DS: $0.35 \mathrm{~L} / \mathrm{min})$. 
LMH at low DS concentration condition), although the effect of the FS flow rate was not dominantly than DS flow rate during the HFFO operation. This indicates that the DS flow rate affected the water flux more strongly than the FS flow rate may be due to the flow path diameter and the retention time in the HFFO element. In the HFFO element, the DS flow path was $85 \mu \mathrm{m}$ (based on inner diameter), and this narrow flow path could significantly enhance the dilution in the channel per unit area (reducing the water flux) (referring Supplementary Tables 1 and 2). However, the FS flow path in the HFFO element did not exist (like a submerged type), and the membranes were packed in a PVC cell with a diameter of $90 \mathrm{~mm}$ and a length of $280 \mathrm{~mm}$. Hence, when the DS and FS flow rates were 0.35 and $1.50 \mathrm{~L} / \mathrm{min}$, respectively, and a DS concentration of $35,000 \mathrm{mg} / \mathrm{L}$ was used, the highest water flux $\left(1.24 \mathrm{~L} / \mathrm{m}^{2} \mathrm{~h}, \mathrm{LMH}\right)$ was observed, which was approximately double the flux when the DS concentration was $10,000 \mathrm{mg} / \mathrm{L}$. Interestingly, the overall RSF tendency was more affected by DS flow rates than FS flow rate (e.g., FS 0.7/DS 0.2: 0.0139 gram per square meter per hour (GMH) to FS 0.7/DS 0.35: $0.0266 \mathrm{GMH}$ at $25,000 \mathrm{mg} / \mathrm{L}$ DS concentration). The RSF increased when the DS flow rate was increased, like the water flux pattern (refer to Supplementary Tables 1 and 2). However, the RSF tendency does not increase proportionally as well as the water flux tendency, and the fluctuation is relatively high ${ }^{26,32}$. It is a relatively small amount of salt mass transport phenomenon, which requires clear identification through future lab-scale experiments. In contrast, when the DS flow rate was increased from 0.20 to $0.35 \mathrm{~L} / \mathrm{min}$, the RSF value increased, whereas the RSF value decreased as the FS flow rate was increased over the entire range of the DS concentrations. The RSF showed a decreasing pattern with an increase in DS concentrations (from 10,000 to $35,000 \mathrm{mg} / \mathrm{L}$ ). It should be noted that the HFFO element showed a relatively low water flux and RSF compared with the different types of FO elements. In previous studies, water fluxes of spiral-wound FO (SWFO) and plate-frame FO (PFFO) elements were 26.5 and 17.7 $\mathrm{LMH}$, respectively. In addition, the RSF values were observed as 12.4 and $8.4 \mathrm{~g} / \mathrm{m}^{2} \mathrm{~h}(\mathrm{GMH})$, respectively, at a DS concentration of $35,000 \mathrm{mg} / \mathrm{L}^{26,28,33,36}$. However, at 35,000 mg/L, the HFFO showed 0.7-1.3 LMH of water flux (around 20 times less than that of SWFO and PFFO) and $0.005-0.030$ GMH of RSF, which is much less than the other elements. Therefore, in the case of the HFFO element, the influence of process operating conditions is not serious, which indirectly shows that RSF consideration is not required for HFFO-RO-sHFFO process operation.

A lower water flux can be overcome slightly by operating the $\mathrm{FO}$ in the PAO mode. As indicated in Fig. 1c, d showing the HFFO operation results in the PAO mode, when the FS and DS flow rates were increased from 0.7 to 1.5 and 0.2 to $0.35 \mathrm{~L} / \mathrm{min}$, respectively, with an applied pressure of 3 bar, the water flux was approximately double (from 1.39 to $2.33 \mathrm{LMH}$ ) that of the FO mode (without any applied pressure) under the same conditions (referring the black dot circle). With the addition of artificial pressure, the DS dilution rate was observed to be a maximum of $408 \%(35,000 \mathrm{mg} / \mathrm{L}, \mathrm{FS} 1.5$, DS $0.35 \mathrm{~L} / \mathrm{min}, 2 \mathrm{bar})$ and a minimum of $131 \%(15,000 \mathrm{mg} / \mathrm{L}$, FS 0.7 , DS $0.35 \mathrm{~L} / \mathrm{min}, 3$ bar). Interestingly, when the DS concentration was similar to the seawater level $(35,000 \mathrm{mg} / \mathrm{L})$, the specific RSF (SRSF = RSF/water flux $(\mathrm{g} / \mathrm{L})$ ) in the PAO mode was much lower than that in the $\mathrm{FO}$ mode $(\mathrm{PAO}=$ $0.008 \mathrm{~g} / \mathrm{L}$ and $\mathrm{FO}=0.018 \mathrm{~g} / \mathrm{L}$ ) under the same conditions (FS and DS flow rates $=1.50$ and $0.35 \mathrm{~L} / \mathrm{min}$, respectively). This indicates that the HFFO operation in the PAO mode can be beneficial for stable water reuse with the pretreatment option for seawater desalination.

Detailed water flux, RSF, SRFS values, DS dilution rate, and diluted DS conc. in the FO and PAO modes can be found in Supplementary Tables 1 and 2, respectively.

\section{Feasibility of sHFFO}

For the characteristics (concept) of FO-RO-sHFFO desalination process, the sHFFO process was simulated under the HFFO operation in the PAO mode depending on the sea level (from the surface of the sea); various natural water pressures can be applied to the membrane by gravity, water density, and depth, and the sHFFO faced an inevitable difference in concentrations between the FS (seawater) and DS (RO brine). Therefore, during this experiment, the FS concentration was changed from 10,000 to $25,000 \mathrm{mg} / \mathrm{L}$, the DS concentration was changed from 35,000 to $80,000 \mathrm{mg} / \mathrm{L}$, and pressures ranging from 2 to 4 bar were applied to the FS side.

Figure $2 \mathrm{a}, \mathrm{b}$ shows the water flux and RSF values, respectively, depending on the concentration differences between the FS and DS (DS-FS) and the applied pressure to the FS. The water flux values increased continuously with increasing FS flow rates, applied pressures, and concentration differences. With the pressure of $4 \mathrm{bar}$, the highest water flux values obtained were $3.92,1.04$, and 1.21 $\mathrm{LMH}$ at the FS flow rates of $1.5,1.0$, and $0.7 \mathrm{~L} / \mathrm{min}$, respectively (DS flow rate $=0.35 \mathrm{~L} / \mathrm{min}$ and concentration difference between FS
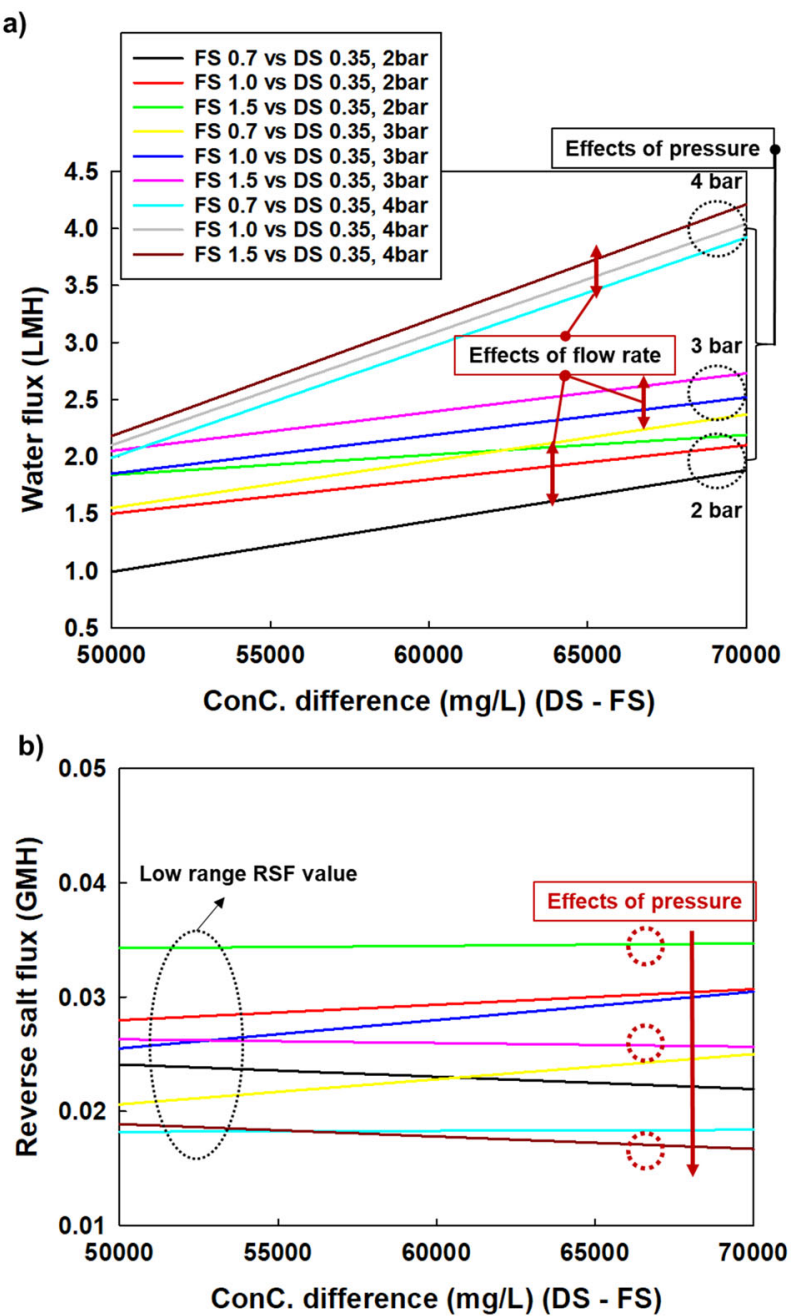

Fig. 2 Water flux and RSF variation at various operation conditions with ionic strength in FS. Panels $\mathbf{a}$, $\mathbf{b}$ show the water flux and RSF values of PAO mode HFFO element at the various concentration and pressure conditions. Synthetic seawater $(\mathrm{NaCl})$ as FS, synthetic seawater or brine $(\mathrm{NaCl})$ as $\mathrm{DS}$, FS concentration of $10,000-35,000 \mathrm{mg} / \mathrm{L}$, DS concentrations from 35,000 to $80,000 \mathrm{mg} / \mathrm{L}$, and pressures of 2,3 , and 4 bar. Flow rates: FS: $0.7,1.0$, and $1.5 \mathrm{~L} / \mathrm{min}$, and DS: $0.35 \mathrm{~L} / \mathrm{min}$. 
and $\mathrm{DS}=70,000 \mathrm{mg} / \mathrm{L}$ ). However, the RSF values were relatively stable compared with those in the FO mode. This may be due to the applied pressure of the FS hindering the salt passage from the DS to the FS (RSF) during the HFFO operation. In addition, the applied pressure provided a positive effect on the performance, and as expected, when there was a variation in the FS and DS concentrations, the FS flow rate and applied pressure to the FS positively influenced the FO performance (i.e., water flux and RSF) ${ }^{37}$.

\section{Dilution effect of HFFO (seawater intake and brine management)}

Figure $3 a, b$ presents the DS dilution rates and diluted DS concentrations according to the DS and FS flow rates and operation modes (FO and PAO) at the DS concentration of $35,000 \mathrm{mg} / \mathrm{L}$. For the HFFO mode (Fig. 3a), the DS dilution rates were over 150 and $200 \%$ when the DS flow rates were 0.20 and $0.35 \mathrm{~L} / \mathrm{min}$, respectively. This difference occurred by changing the DS volume and permeation ratio (water flux) as the DS flow rate was changed (Supplementary Tables 1 and 2). Accordingly, the final diluted DS concentrations ranged from 16,000 to $23,000 \mathrm{mg} /$ $\mathrm{L}$, depending on the flow rate. However, when the pressure was applied to the FS side at a constant DS flow rate of $0.35 \mathrm{~L} / \mathrm{min}$ and varied FS flow rates ( 0.7 to $1.5 \mathrm{~L} / \mathrm{min}$ ), the diluted DS concentrations decreased further to 11,000 and $9,600 \mathrm{mg} / \mathrm{L}$ (at operating pressures of 2 and 3 bar, respectively).

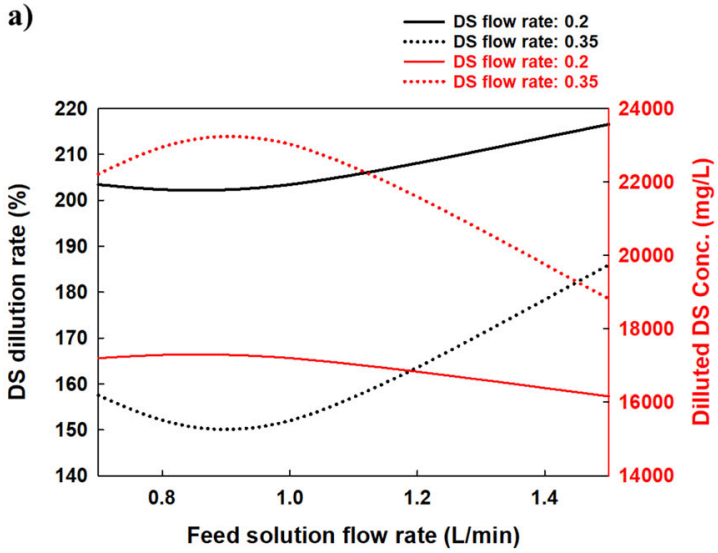

c)

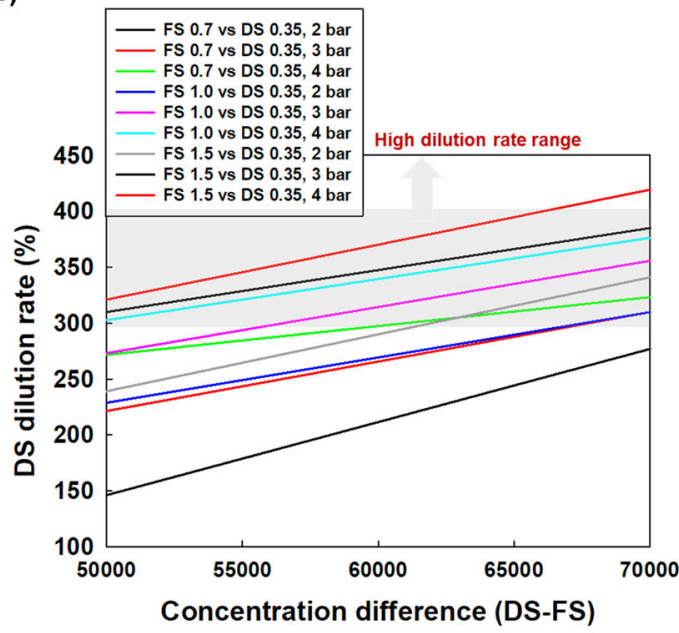

Figure $3 c$ shows the dilution rate and diluted DS concentration depending on the differences between the FS and DS concentrations ranging from 50,000 to $70,000 \mathrm{mg} / \mathrm{L}$, the FS flow rate, and the applied pressure. When the difference between the FS and DS concentrations was $50,000 \mathrm{mg} / \mathrm{L}$ with the operating conditions of FS flow rate $=0.70$, DS flow rate $=0.35 \mathrm{~L} / \mathrm{min}$, and applied pressure $=2$ bar, the diluted DS concentration and dilution rate were observed to be $34,000 \mathrm{mg} / \mathrm{L}$ and $146 \%$, respectively. If the HFFO element is operated under the suggested conditions (i.e., sHFFO), the DS concentration can be equalized to that of the seawater. Therefore, this condition can be used to optimize (Case 7 in Table 1) the HFFO-based infinity seawater desalination process (FO-RO-sHFFO). With a difference in the concentrations across the membrane and the application of pressure to the FS (in PAO mode), various dilution rates and diluted DS concentrations were observed (Fig. 3c) as to the experiment of the condition where the concentration difference exists (Fig. 3b). This occurs because the external concentration polarization has a significant effect on the FO performance when differential concentrations are presented, and more significant internal concentration polarization occurs with a difference in concentration. With no difference between the FS and DS concentrations, when the FS and DS flow rates were 1.5 and $0.35 \mathrm{~L} / \mathrm{min}$, respectively, and a pressure of $3 \mathrm{bar}$ was applied to the FS, a dilution rate of more than $400 \%$ dilution rate and a diluted DS concentration of approximately $8500 \mathrm{mg} / \mathrm{L}$ could be achieved (Figs. 2 and 3). However, when the difference

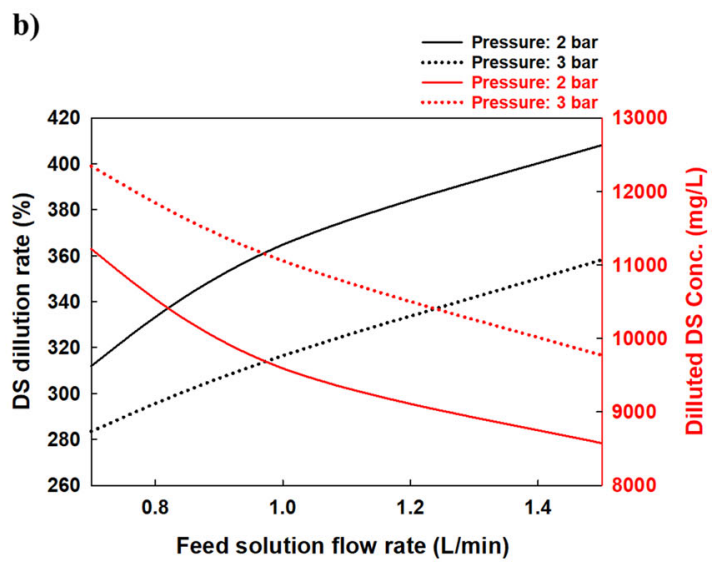

d)

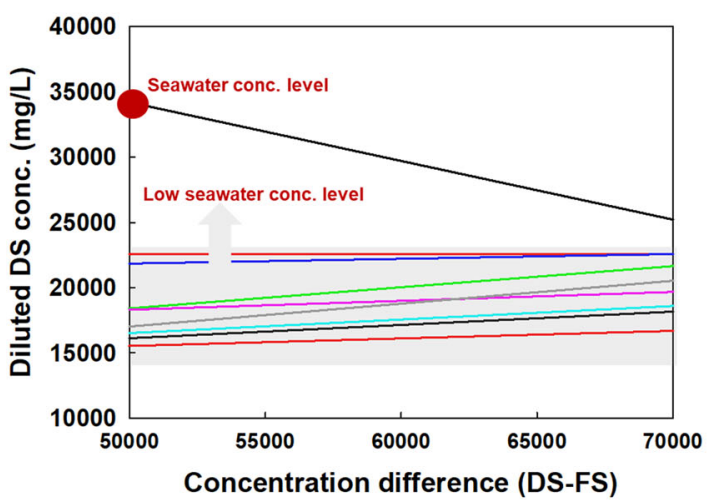

Fig. 3 DS dilution rate and concentration at various operation conditions. Panels $\mathbf{a}, \mathbf{b}$ show the DS dilution rate and concentration at the FO and PAO mode operation. Panels $\mathbf{c}$, $\mathbf{d}$ show the DS dilution rate and concentration with varying concentration differences between FS and DS. 
Table 1. Operating pressure and permeate quality of SWRO for different cases (the cases were selected based on the performance test results, with a total of eight cases: four in FO mode and four in PAO mode, using a two-stage RO as the control) and a total plant recovery rate of $60 \%$.

\begin{tabular}{|c|c|c|c|c|c|c|c|c|c|c|}
\hline & & SWRO & Case 1 & Case 2 & Case 3 & Case 4 & Case 5 & Case 6 & Case 7 & Case 8 \\
\hline 50 & Perm. conc. (mg/L) & 257.0 & 134.2 & 165.6 & 114.5 & 122.2 & 67.9 & 77.2 & 78.4 & 114.5 \\
\hline \multirow[t]{2}{*}{60} & $P$ (bar) & 75.8 & 41.2 & 49.5 & 36.2 & 38.2 & 25.0 & 27.2 & 27.5 & 36.2 \\
\hline & Perm. conc. (mg/L) & 312.4 & 160.7 & 199.3 & 136.6 & 146.0 & 79.6 & 91.0 & 92.4 & 136.6 \\
\hline
\end{tabular}

Table 2. Operating pressure and permeate quality of SWRO for the different cases (selected based on the performance test results, with a total of eight cases: four in FO mode and four in PAO mode, using the two-stage RO as the control), with a total plant recovery rate of $80 \%$.

\begin{tabular}{|c|c|c|c|c|c|c|c|c|c|c|}
\hline$R(\%)$ & & Two-stage RO & F1.5-D0.35 & F1.0-D0.35 & F1.5-D0.20 & F0.7-D0.20 & $\begin{array}{l}\text { PAO (3 bar) } \\
\text { F1.5-D } 0.35\end{array}$ & $\begin{array}{l}\text { PAO (3 bar) } \\
\text { F1.0-D0.35 }\end{array}$ & $\begin{array}{l}\text { PAO ( } 2 \text { bar }) \\
\text { F0.7-D } 0.35\end{array}$ & $\begin{array}{l}\text { PAO (2 bar) } \\
\text { F1.5-D0.35 }\end{array}$ \\
\hline & Perm. conc. (mg/L) & 567.8 & 305.0 & 375.3 & 259.8 & 277.6 & 149.1 & 171.7 & 174.5 & 259.8 \\
\hline & $\mathrm{SEC}\left(\mathrm{kWh} / \mathrm{m}^{3}\right)$ & 6.02 & 2.88 & 3.62 & 2.43 & 2.60 & 1.46 & 1.65 & 1.67 & 2.43 \\
\hline
\end{tabular}

between the FS and DS concentrations was $70,000 \mathrm{mg} / \mathrm{L}$, approximately $350 \%$ of the dilution rate was enabled and the process could dilute the DS concentration to $22,580 \mathrm{mg} / \mathrm{L}$ (detailed water flux, RSF, and SRFS values can be found in Supplementary Tables 3). In addition, the expected operating pressures and permeate concentrations with the SWRO process after the HFFO process were simulated under various operating conditions in the cross-flow HFFO process (nine cases including a two-stage SWRO) and two different recovery rates in the RO process (50 and 60\%) (Table 1). A total of nine cases, including a control (two-stage RO), were selected based on the HFFO element performance evaluation results under various operating conditions (Sections 1 and 2): four conditions in the FO mode (Cases 1-4) and four conditions in the PAO mode (Cases 5-8). The same operating conditions were applied to the HFFO and SHFFO elements in the HFFO-based infinity desalination process. Depending on the cases, the required pressure and final permeate concentration of the downstream SWRO process were predicted.

However, in the FO-RO-sHFFO desalination process, when the downstream two-stage SWRO process is operated at a recovery rate of $60 \%$, the brine concentration is lower than that of the seawater, making the operation of the sHFFO process impossible. Therefore, for the two-stage SWRO process operated at a higher recovery rate $(80 \%)$, at which the brine concentration discharged is approximately $60,000 \mathrm{mg} / \mathrm{L}$, the operation pressure, permeate concentration, and specific energy consumption (SEC) value were recalculated, as shown in Table 2. In the two-stage SWRO, for Cases 1 and 2, the operating pressures of the SWRO calculated under such conditions were unacceptable. However, in Case 5, it was still possible to operate under lower pressure ( 37.9 bar) than with the two-stage SWRO process.

The detailed SEC values, operation pressures of the SWRO process, and the permeate concentrations at various recovery rates can be found in Supplementary Tables 4, 5, and 6.

In the following section, an economic evaluation is described in terms of energy, comparing i) two-stage RO versus FO-RO-sHFFO and ii) SWRO with ZLD versus FO-RO-sHFFO.

\section{Energy evaluation (two-stage SWRO vs FO-RO--sHFFO)}

To evaluate the economic benefits of the FO-RO-sHFFO process, the SEC of both the FO and RO processes were calculated, as shown in Fig. 4a, b. During the calculation, the plant capacity was assumed to be $100,000 \mathrm{~m}^{3} /$ day. The pump efficiency and energy consumption were $90 \%$ and $0.1 \mathrm{kWh} / \mathrm{m}^{3}$, respectively. Owing to the structural characteristics of the element-scale HFFO process, the energy requirement of the FS pump is higher than that of the DS pump (Fig. 4a). Depending on the HFFO operating conditions (Table 1), the operating energy on the FO side also fluctuates, and the calculated SEC values of the RO process were different (Fig. 4b). Surprisingly, regarding the total SEC values when considering the energy requirement of both the $\mathrm{FO}$ and $\mathrm{RO}$ sections (Fig. 4c), the lowest energy requirement $\left(1.49 \mathrm{kWh} / \mathrm{m}^{3}\right)$ was observed in Case 5 (FS flow rate $=1.5 \mathrm{~L} / \mathrm{min}$, DS flow rate $=$ $0.35 \mathrm{~L} / \mathrm{min}$, and applied pressure $=3 \mathrm{bar}$ ), and approximately $62 \%$ of energy was conserved compared with the two-stage RO process. Consequently, the energy costs based on the SEC value of the FO and RO were calculated (Fig. 4d). The operation period of the desalination plant was assumed to be 20 years. The cost results are similar to those of the SEC, and the FO-RO-HFFO can save approximately $66 \%$ of the cost compared with the two-stage $\mathrm{RO}$ process (two-stage $\mathrm{RO}=\mathbf{2 8 0}$ million USD and FO-RO-HFFO process (Case 5) $=96$ million USD). Furthermore, when the recovery rate was increased from 60 to $80 \%$, the SEC value of the two-stage SWRO was increased to $6.02 \mathrm{kWh} / \mathrm{m}^{3}$. However, approximately 170 million USD is saved over the lifetime of the plant compared with the two-stage SWRO at a recovery of $60 \%$ (Fig. 4c and Supplementary Fig. S7).

The amortized CAPEX of the FO-RO hybrid process was calculated based on Case 5 considering the installation/service, legal/professional, intake/outfall, pretreatment, piping/high alloy, civil engineering, pumps, pressure vessels, membranes, equip$\mathrm{ment} / \mathrm{materials}$, and the design/professional costs. In the case of the HFFO, the incorporated desalination process, the costs of pretreatment, and the intake/outfall were excluded. This exclusion also results in significant CAPEX savings: approximately $15.8 \%$ (20 million USD) of the amortized total CAPEX ${ }_{\mathrm{RO}}$ and $1.2 \%$ (43 million USD) of the amortized total CAPEX $\mathrm{FO}_{\mathrm{F}}$ in the HFFO-incorporated 
a)

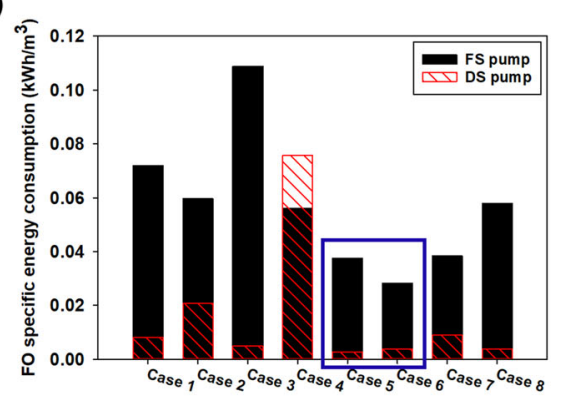

b)

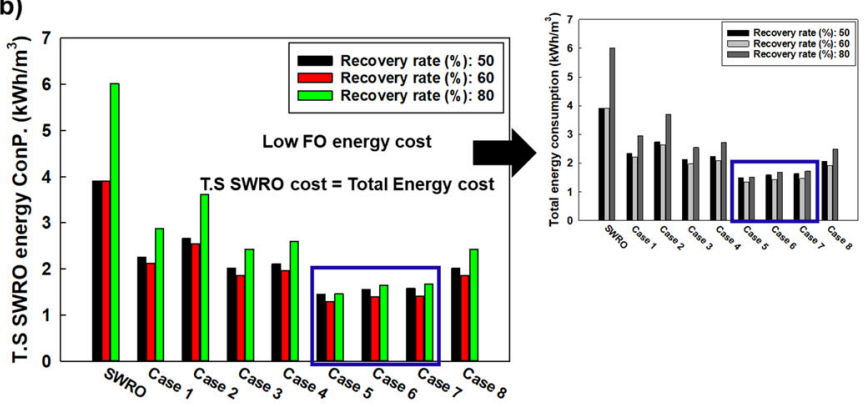

c)

Design period (yr): 20

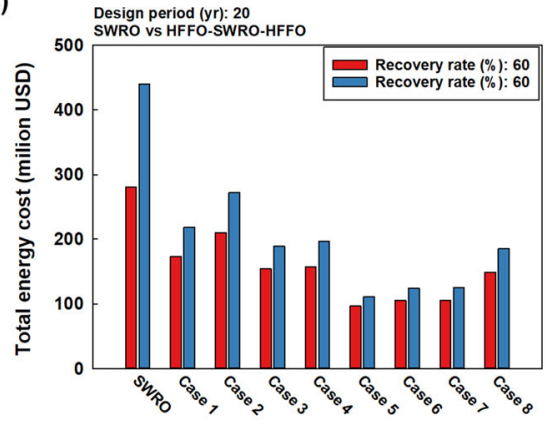

Fig. 4 Energy consumption values (SEC) compared with two-stage RO process at the different recovery rates. Panels a, b show the energy consumption values (SEC) compared with two-stage RO process at the different recovery rates. Panel c shows the total energy cost of the FO-RO-HFFO process compared with the RO process at 60 and $80 \%$ recovery rate.

desalination process including the intake/outfall and pretreatment. Consequently, comparing the total cost of the HFFOincorporated desalination process with the conventional FO-RO hybrid process based on the conditions and performance of Case 5, the FO-RO-sHFFO desalination process can save as much as 63 million USD during a 20-year period. Detailed data on the economic evaluation are presented in Supplementary Fig. 1.

\section{Economic and environmental impact evaluation (ZLD vs. brine circulation-no brine discharge)}

Conventional seawater desalination plants produce clean water, although high-salinity brine is also produced ${ }^{21,24}$. Depending on the recovery rate, the quality and quantity of the brine vary. In this section, an evaluation of the energy cost was conducted by comparing the HFFO-based infinity seawater desalination process with a two-stage SWRO combined with the ZLD process. The ZLD process can be defined to remove all liquid waste from the desalination process, reduce any harmful environmental effects, and meet the required regulations ${ }^{20}$. However, the HFFO-based infinity desalination process does not discharge the brine because the brine is recirculated (or diluted) through the HFFOs and then re-fed into the first HFFO process. Therefore, the HFFO-based infinity desalination process presents environmental cost benefits. As shown in Fig. 5, the energy cost of the two-stage SWRO with a brine concentrator and crystallizer was 1191 million USD. The resulting costs were calculated based on a $100,000 \mathrm{~m}^{3} /$ day plant capacity and $60 \%$ recovery rate. In addition, the brine capacity (brine concentrator feed water) was $400,000 \mathrm{~m}^{3} /$ day from the twostage SWRO process, and the recovery rate of the brine concentrator was $80 \%$. The inlet flow rate of the downstream crystallizer was $8000 \mathrm{~m}^{3} /$ day and the recovery rate was assumed to be $100 \%$. The driving force of the brine concentrator and crystallizer is heat energy, and the high energy consumption is required for thermal-based desalination methods (i.e., MED and MSF)). However, as mentioned in the previous section, the HFFObased infinity desalination process does not require a circulation pump for the FS and DS to recover the brine to the seawater concentrations. Therefore, the HFFO-based infinity desalination

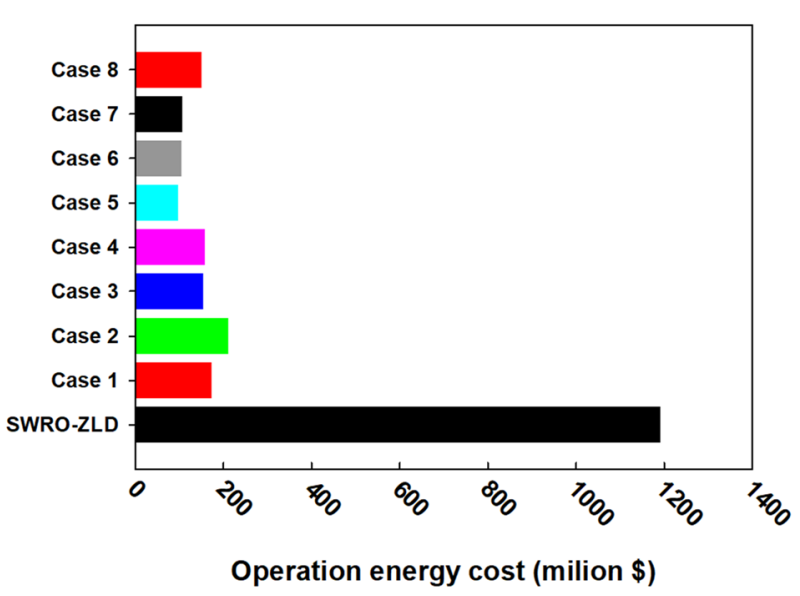

Fig. 5 Energy cost of two-stage SWRO with ZLD (brine concentrator-crystallizer) and FO-based desalination process (brine circulation process, no brine discharge). ZLD plant capacity = $40,000 \mathrm{~m}^{3} /$ day (two-stage SWRO process recovery rate $=60 \%$ ), energy consumption by brine concentrator $=19.8 \mathrm{kWh} / \mathrm{m}^{3}$ (recovery rate $=80 \%$ ), and crystallizer $=56.8 \mathrm{kWh} / \mathrm{m}^{3}$ (recovery rate $=$ $100 \%)$.

process can save more than 1 billion USD in energy costs over a 20-year period.

If the recovery rate is fixed, the concentration and volume of the brine in the FO-RO-sHFFO process differ from those during the production of $100,000 \mathrm{~m}^{3} /$ day for the stand-alone two-stage SWRO process. If the recovery rate is $60 \%$ in the stand-alone twostage SWRO process, the concentration and flow rate of the brine can reach $87,500 \mathrm{mg} / \mathrm{L}$ and $66,667 \mathrm{~m}^{3} /$ day, respectively. For the FO-RO--sHFFO process, to achieve a final product volume of $100,000 \mathrm{~m}^{3} /$ day, the SWRO can be operated at low pressures (25 bar) and a low inlet flow rate $\left(46,519 \mathrm{~m}^{3} /\right.$ day) because the DS, which is diluted by the wastewater during the first HFFO process, can be fed into the SWRO process. However, for the second HFFO 
process (sHFFO) used in the FO-RO-sHFFO process (infinite circulation for zero brine discharge), the concentration of brine from the SWRO must be higher than that of the seawater for a sustainable operation. This means that the recovery rate of the SWRO process must be $>60 \%$. Therefore, an additional economic evaluation was conducted with a fixed capacity of the SWRO process, and it was found that reasonable conditions for the SWRO are as follows: recovery rate $=45 \%$, influent $=222,222 \mathrm{~m}^{3} /$ day, final product $=100,000 \mathrm{~m}^{3} /$ day, operation pressure $=59.2 \mathrm{bar}$, and brine concentration $=63,636 \mathrm{mg} / \mathrm{L}$. Considering a brine concentration suitable for the sHFFO process, a recovery rate of approximately $85 \%$ was recommended to achieve an optimal operation. In this case, the operating pressure is $37.9 \mathrm{bar}$, and the brine concentration and flow rate are $65,127 \mathrm{mg} / \mathrm{L}$ and $33,333 \mathrm{~m}^{3} /$ day, respectively. Under modified conditions, the water production of the FO-RO-sHFFO process is approximately twice that of the stand-alone two-stage SWRO process. Detailed economic evaluation results can be found in Supplementary Fig. 1.

\section{DISCUSSION}

This study introduced a low-energy desalination process with minimal environmental impacts comprised of a cross-flow HFFO, $\mathrm{RO}$, and SHFFO. The performance of the HFFO-based infinity desalination process was evaluated under various operating conditions. The energy costs of this process was compared with a two-stage RO, FO-RO hybrid process, and two-stage RO with ZLD. To summarize the results of each sector, when the HFFO element is evaluated at various operational mode (FO and PAO mode, flow rate, and DS concentration changing), as the structural characteristics of the HFFO element (narrow DS flow path and non-exist FS flow path), the FS is affected less by changing the flow rate and concentration than the $\mathrm{DS}^{38}$. Conversely, the water flux increased with an increase in the DS concentration. In addition, RSF during the HFFO operation can be negligible, which is a considerable benefit to reusing wastewater. In other aspects, the passage of salt passing from the DS to the wastewater used as the FS during the FO operation is not a cause for concern. However, the RSF values under all conditions tested in the PAO mode were similar to those in the FO mode, indicating that the applied pressure has a positive effect on the water flux only and has no significant effect on the RSF ${ }^{39}$. As stated earlier, this process was applied to dilute the seawater brine (similar to the DS for the sHFFO) produced from the RO process with seawater. In addition, the natural osmotic pressure differential between the RO brine and seawater was used as well as the naturally occurring water pressure depending on the water level (or depth). Furthermore, clean seawater (no pretreatment but it is clean) was fed to the desalination plant (FO-RO). Water flux, RSF values, dilution rate, and diluted DS concentration were evaluated for the sustainability and applicability of HFFO performance regarding intake or brine management (diluted with seawater). Results show that for the FO-RO-sHFFO desalination process, the diluted DS concentration, which is fed into the HFFO process, should be similar to the seawater concentration $(35,000 \mathrm{mg} / \mathrm{L})$ because dilution continues until reaching the concentration level of seawater during the sHFFO process.

For the economics aspect, the operating pressure and recovery rate of the RO process are directly related to the OPEX in the desalination plant, subsequently affecting the total water production cost. It is therefore essential to calculate the energy cost by considering the FS concentration, operation pressure, and recovery rate. These calculations enable an evaluation of the economic benefits of the HFFO-incorporated FO-RO hybrid desalination process (FO-RO-sHFFO). It should be noted that the HFFO process has several advantages when applied to the downstream SWRO process: (i) a high surface area in the module $\left(31.5 \mathrm{~m}^{2}\right)$, (ii) a high packing density $\left(55.6 \mathrm{~m}^{2} / \mathrm{m}^{3}\right)$, (iii) a high DS dilution rate (up to approximately $400 \%$ ), and (iv) a low RSF (0.008-0.034 GMH). As a result, sustainable brine management (no brine discharge) combined with energy-free seawater intake is possible because a relatively small number of HFFO elements (sHFFO) are required to dilute (or recover) the brine generated from the SWRO process to the seawater level while minimizing salt loss. Therefore, the performance results sufficiently demonstrated the feasibility of the HFFO-based infinity desalination process in overcoming the limitations of the SWRO process (operating energy). In addition, the HFFO-based infinity desalination process can achieve ZLD because the brine is not produced from the process and the intake and pretreatment systems are eliminated. The ZLD reduces both the CAPEX and OPEX because clean seawater is taken into the HFFO system by the naturally differential osmotic pressure.

The whole results indicate that the HFFO-based infinity desalination process can achieve a high DS dilution rate (up to $400 \%$ ) and lower operating pressures for the RO process. In addition, the energy cost evaluation revealed favorable results for the HFFO-based infinity desalination process under various operating conditions compared with the RO process. These results can open a new avenue for the FO and desalination industry. From the research results, we can conclude that the HFFO-based infinity desalination process is sustainable, environmentally friendly, and economical. First, without a pretreatment process of the DS (seawater), sustainable operations are possible with an infinity cyclic loop configuration of the first HFFO $\rightarrow$ SWRO $\rightarrow$ sHFFO process. Second, the process can be operated at a higher recovery rate $(\sim 80 \%)$ than the conventional SWRO process, thus producing a large amount of permeate. At the same time, the produced brine is directly fed into the sHFFO process instead of being discharged to the marine ecosystem. As a result, there is no environmental brine loading or posttreatment steps, which are limitations in the conventional SWRO process. Third, the HFFO-based infinity desalination process can save 63 million USD over 20 years compared with a conventional SWRO-based desalination plant because there are no DS pretreatment installation, operation, and maintenance costs and the SWRO process can be operated at low pressures (i.e., 25 bar). However, the HFFO-based infinity desalination process needs further optimization, and verification studies must be conducted regarding membrane fouling and applications for commercialization. In summary, the FO-RO-sHFFO process has numerous advantages over the two-stage SWRO with the ZLD process. First, brine discharge or treatment is not required, which results in no additional energy costs (further environmental load reduction). Second, if the FO-RO-sHFFO hybrid process targets the same water production, the final water cost or the plant capacity can be reduced. Third, because the brine is recirculated continuously, a seawater pretreatment process is not required, thus reducing both the CAPEX and OPEX costs for intake, pretreatment, and brine discharge.

\section{METHODS}

\section{Experimental setup and experimental conditions}

In this study, an HFFO element was evaluated under various operating conditions (Fig. 6a) to evaluate the FO-RO-sHFFO concept (Fig. 6b). The specifications of the HFFO membrane can be found in Supplementary Table 7. The element-scale HFFO system is comprised of two circulation pumps (Longer Pump WT3000-1FA, China), digital pressure gauges (Omegadyne Inc., Model PX319-050G5V, Sunbury, OH, US), and flow rate meters (DLCL, MiLESEEY, China) on each side of the system. A digital balance (Potable Bench, CAS, Republic of Korea) and a conductivity meter (Orion 4 Star, Thermo Scientific, Albany, USA) were installed in the FS tank to measure the change in weight and conductivity at 30-s intervals for the calculation the water flux and RSF. Detailed equations used to calculate the water flux and RSF can be found in the Supplementary information. The element-scale HFFO experiments were conducted under various operating conditions (Table 3). For the test in FO mode (to evaluate the 
a)

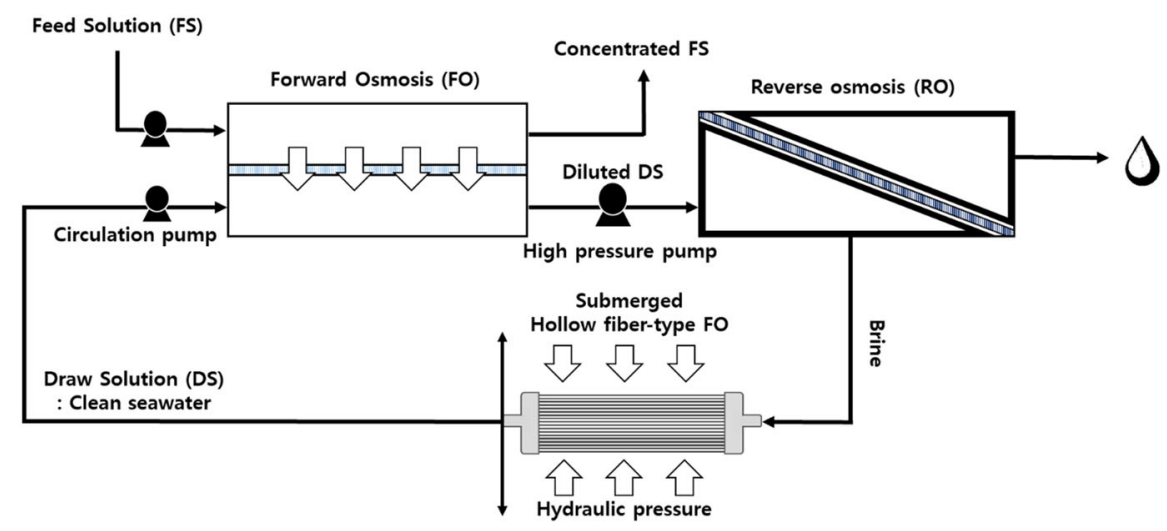

b)

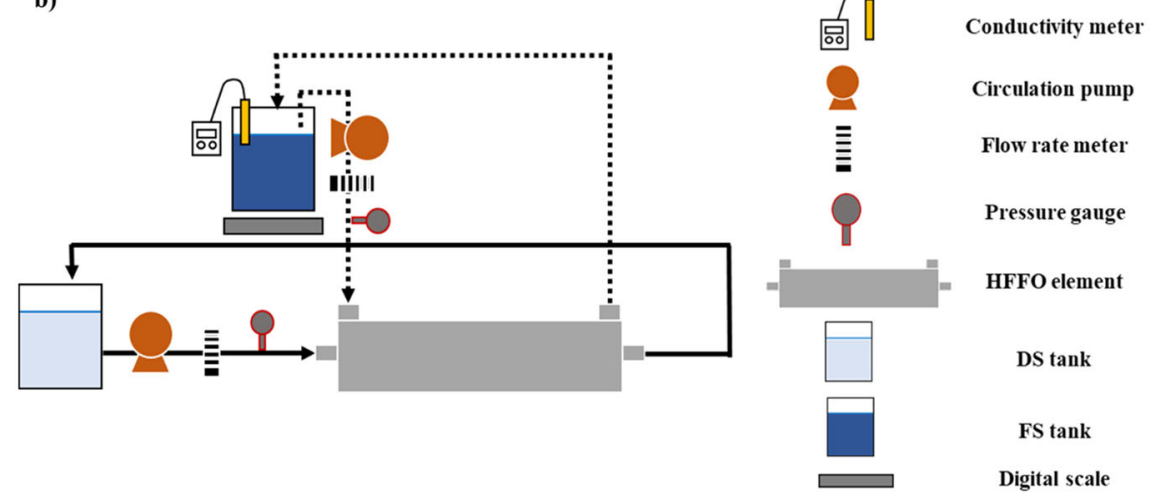

Fig. 6 Schematic of an HFFO-incorporated FO-RO hybrid desalination process (FO-RO-sHFFO) and an element-scale HFFO testing system. Panels $\mathbf{a}$ and $\mathbf{b}$ show the schematic of an HFFO-incorporated FO-RO hybrid desalination process (FO-RO-sHFFO) and an elementscale HFFO testing system (FS and DS were fed into the upper and side ports, respectively. The operation mode was counter current and the side inlet flow rate and pressure were continuously maintained).

\begin{tabular}{|c|c|c|}
\hline Operation mode & FO mode & PAO mode \\
\hline $\begin{array}{l}\text { FS type and } \\
\text { conc. (mg/L) }\end{array}$ & DI water & $\begin{array}{l}\text { Synthetic seawater } \\
(\mathrm{NaCl} 99 \%) \text { and } \\
10,000-25,000\end{array}$ \\
\hline $\begin{array}{l}\text { DS type and } \\
\text { conc. (mg/L) }\end{array}$ & $\begin{array}{l}\text { Synthetic seawater } \\
\text { ( } \mathrm{NaCl} 99 \% \text { ) and } \\
10,000 \text { to } 35,000\end{array}$ & $\begin{array}{l}\text { Synthetic seawater to } \\
\text { brine ( } \mathrm{NaCl} 99 \%) \\
35,000-80,000\end{array}$ \\
\hline $\begin{array}{l}\text { FS flow rate (L/min) } \\
\text { CFV (m/s) }\end{array}$ & $\begin{array}{l}0.7,1.0, \text { and } 1.5 \\
0.016,0.02 \text { and } 0.03\end{array}$ & $0.7,1.0$, and 1.5 \\
\hline $\begin{array}{l}\text { DS flow rate }(\mathrm{L} / \mathrm{min}) \\
\text { CFV }(\mathrm{m} / \mathrm{s})\end{array}$ & $\begin{array}{c}0.20 \text { and } 0.35 \\
4.7 \text { and } 8.3\end{array}$ & 0.35 \\
\hline $\begin{array}{l}\text { Operation } \\
\text { pressure (bar) }\end{array}$ & 0 & 2,3 , and 4 \\
\hline
\end{tabular}

first FO process in Fig. 1a), deionized (DI) water (resistivity $>18 \mathrm{M} \Omega / \mathrm{cm}$ ) and a synthetic seawater solution ( $99 \% \mathrm{NaCl}$ ) (Samchun Chemicals, Republic of Korea) were applied as the FS and DS, respectively. Here, the performance of the first HFFO element was evaluated in FO mode within the range of seawater concentrations. Tests using the HFFO element in PAO mode were conducted under different osmotic pressures within the range of the difference between the brine and seawater concentrations to evaluate the second FO (sHFFO applied, with natural pressure altered by different water levels), with pressures ranging from 2 to 4 bar. In this case, the FS concentration was within the seawater range and the DS concentration was within the brine range. In addition, the performance of the HFFO element was evaluated at various flow rates on both sides (the flow rate was selected as the performance evaluation factor, and its ranges were provided by the manufacturer). In the FO mode, the flow rates of the FS and DS were varied at $0.7,1.0$, and 1.5 and at 0.20 and $0.35 \mathrm{~L} / \mathrm{min}$, respectively. In the PAO mode, the same FS flow rates were used, whereas the DS flow rate was fixed at $0.35 \mathrm{~L} / \mathrm{min}$.

The HFFO experiment was started with $30 \mathrm{~L}$ of DS and $60 \mathrm{~L}$ of FS, and when the DS dilution rate reached $100 \%$, the experiment was stopped. The equipment was then physically cleaned (forward flushing using DI water) for the next experiment

\section{Energy cost evaluation}

An energy cost evaluation was conducted based on the performance results to obtain the feasibility of the HFFO-based infinity desalination process, which causes minor environmental impacts, using a Microsoft 2013 Excel calculation sheet and a reverse osmosis system analysis simulator ${ }^{27,34}$. In this study, some assumptions used in previous studies were selected ${ }^{6,27,34}$ and applied for the economic evaluation comparing this process with the two-stage SWRO process (Supplementary Tables 8 and 9). Ultrafiltration-membrane-treated seawater and secondary wastewater effluent were used as the DS and FS for the first FO (in both the twostage SWRO process and the FO-RO-sHFFO system). The FO element cost, including the FO module cost, of $\$ 7000$ was used in the economic evaluation. The optimized HFFO element operating conditions (side inlet pressure of the FS and minimum flow and dilution rates of the FS and DS) and numerous serial arrays were fixed for the cost evaluation ${ }^{28}$. Otherwise, all other economic calculations and related factors were the same as those used in previous studies ${ }^{28,30}$. The cost and performance of the HFFO element, the number and capacity of the FS and DS pumps, and the number of HFFO elements in parallel depending on the arrangement, were 
calculated. The methods used in the economic evaluation of the HFFO element and the assumed factors are presented in Supplementary Table 9. Additional detailed economic factors are shown in Supplementary Table 10.

\section{Reporting summary}

Further information on research design is available in the Nature Research Reporting Summary linked to this article.

\section{DATA AVAILABILITY}

The authors confirm that the data supporting the findings of this study are available within the article and its Supplementary materials.

Received: 4 February 2021; Accepted: 11 October 2021; Published online: 09 December 2021

\section{REFERENCES}

1. Amy, G. et al. Membrane-based seawater desalination: present and future prospects. Desalination 401, 16-21 (2017).

2. Shahzad, M. W., Burhan, M., Ang, L. \& Ng, K. C. Energy-water-environment nexus underpinning future desalination sustainability. Desalination 413, 52-64 (2017).

3. Tarnacki, K., Meneses, M., Melin, T., van Medevoort, J. \& Jansen, A. Environmental assessment of desalination processes: reverse osmosis and Memstill ${ }^{\oplus}$. Desalination 296, 69-80 (2012).

4. Miller, S., Shemer, H. \& Semiat, R. Energy and environmental issues in desalination. Desalination 366, 2-8 (2015).

5. Missimer, T. M. \& Maliva, R. G. Environmental issues in seawater reverse osmosis desalination: Intakes and outfalls. Desalination 434, 198-215 (2018).

6. Kim, J. E., Phuntsho, S., Chekli, L., Choi, J. Y. \& Shon, H. K. Environmental and economic assessment of hybrid FO-RO/NF system with selected inorganic draw solutes for the treatment of mine impaired water. Desalination 429, 96-104 (2018).

7. Zarzo, D. \& Prats, D. Desalination and energy consumption. What can we expect in the near future? Desalination 427, 1-9 (2018)

8. Wardenier, N., Liu, Z., Nikiforov, A., Van Hulle, S. W. H. \& Leys, C. Micropollutant elimination by O3, UV and plasma-based AOPs: an evaluation of treatment and energy costs. Chemosphere 234, 715-724 (2019).

9. He, Y. et al. Assessment of energy consumption of municipal wastewater treatment plants in China. J. Clean. Prod. 228, 399-404 (2019).

10. Kim, J. \& Hong, S. Optimizing seawater reverse osmosis with internally staged design to improve product water quality and energy efficiency. J. Membr. Sci. 568, 76-86 (2018).

11. Jeong, K., Park, M. \& Chong, T. H. Numerical model-based analysis of energyefficient reverse osmosis (EERO) process: performance simulation and optimization. Desalination 453, 10-21 (2019).

12. Ahunbay, M. G., Tantekin-Ersolmaz, S. B. \& Krantz, W. B. Energy optimization of a multistage reverse osmosis process for seawater desalination. Desalination 429 , 1-11 (2018).

13. Ghaffour, N. et al. Renewable energy-driven innovative energy-efficient desalination technologies. Appl. Energy 136, 1155-1165 (2014).

14. Kurihara, M. \& Takeuchi, H. SWRO-PRO system in "Mega-ton Water System" for energy reduction and low environmental impact. Water 10, 48-63 (2018).

15. Im, S. J., Choi, J., Jeong, S. \& Jang, A. New concept of pump-less forward osmosis (FO) and low-pressure membrane (LPM) process. Sci. Rep. 7, 14569 (2017).

16. González, D., Amigo, J. \& Suárez, F. Membrane distillation: perspectives for sustainable and improved desalination. Renew. Sustain. Energy Rev. 80, 238-259 (2017).

17. Lee, S., Park, T.-S., Park, Y.-G., Lee, W.-i. \& Kim, S.-H. Toward scale-up of seawater reverse osmosis (SWRO)-pressure retarded osmosis (PRO) hybrid system: a case study of a $240 \mathrm{m3} /$ day pilot plant. Desalination 491, 114429 (2020).

18. Tristán, C. et al. Life cycle assessment of salinity gradient energy recovery by reverse electrodialysis in a seawater reverse osmosis desalination plant. Sustain. Energy Fuels 4, 4273-4284 (2020).

19. ElMekawy, A., Hegab, H. M. \& Pant, D. The near-future integration of microbial desalination cells with reverse osmosis technology. Energy Environ. Sci. 7, 3921-3933 (2014).

20. Giwa, A., Dufour, V., Al Marzooqi, F., Al Kaabi, M. \& Hasan, S. W. Brine management methods: recent innovations and current status. Desalination 407, 1-23 (2017).

21. Heijman, S. G. J., Guo, H., Li, S., van Dijk, J. C. \& Wessels, L. P. Zero liquid discharge: heading for $99 \%$ recovery in nanofiltration and reverse osmosis. Desalination 236, 357-362 (2009)
22. Nayar, K. G., Fernandes, J., McGovern, R. K., Al-Anzi, B. S. \& Lienhard, J. H. Cost and energy needs of RO-ED-crystallizer systems for zero brine discharge seawater desalination. Desalination 457, 115-132 (2019).

23. Zhang, $C$. et al. Designing a next generation solar crystallizer for real seawater brine treatment with zero liquid discharge. Nat. Commun. 12, 998 (2021).

24. Tong, T. \& Elimelech, M. The global rise of zero liquid discharge for wastewate management: drivers, technologies, and future directions. Environ. Sci. Technol. 50, 6846-6855 (2016).

25. Tsai, J.-H. et al. Membrane-based zero liquid discharge: myth or reality? J. Taiwan Inst. Chem. Eng. 80, 192-202 (2017).

26. Im, S.-J., Jeong, S. \& Jang, A. Feasibility evaluation of element scale forward osmosis for direct connection with reverse osmosis. J. Membr. Sci. 549, 366-376 (2018).

27. Im, S. J., Jeong, S., Jeong, S. \& Jang, A. Techno-economic evaluation of an elementscale forward osmosis-reverse osmosis hybrid process for seawater desalination. Desalination 476, https://doi.org/10.1016/j.desal.2019.114240 (2020).

28. Im, S.-J. \& Jang, A. The influence of engineering factors on the efficiency of a spiral wound forward osmosis system: performance and economic evaluation. Desalination 501, https://doi.org/10.1016/j.desal.2020.114884 (2021).

29. Im, S. J., Choi, J., Lee, J. G., Jeong, S. \& Jang, A. Application of volume-retarded osmosis and low-pressure membrane hybrid process for water reclamation. Chemosphere 194, 76-84 (2018).

30. Wan, C. F. \& Chung, T.-S. Techno-economic evaluation of various $\mathrm{RO}+\mathrm{PRO}$ and $\mathrm{RO}+\mathrm{FO}$ integrated processes. Appl. Energy 212, 1038-1050 (2018).

31. Sreedhar, I., Khaitan, S., Gupta, R., Reddy, B. M. \& Venugopal, A. An odyssey of process and engineering trends in forward osmosis. Environ. Sci. Water Res. Technol. 4, 129-168 (2018).

32. Lee, S. \& Kim, Y. C. Performance analysis of plate-and-frame forward osmosis membrane elements and implications for scale-up design. J. Membr. Sci. 550, 219-229 (2018)

33. Song, M., Im, S.-J., Jeong, S. \& Jang, A. Evaluation of an element-scale plate-type forward osmosis: effect of structural parameters and operational conditions. Desalination 430, 15-23 (2018).

34. Kook, S. et al. Serially connected forward osmosis membrane elements of pressure-assisted forward osmosis-reverse osmosis hybrid system: process performance and economic analysis. Desalination 448, 1-12 (2018).

35. Wang, J., Chen, J., Chen, B., Yan, F. \& Xue, Q. Wear behaviors and wear mechanisms of several alloys under simulated deep-sea environment covering seawater hydrostatic pressure. Tribol. Int. 56, 38-46 (2012).

36. Kim, J. et al. Practical considerations for operability of an $8^{\prime \prime}$ spiral wound forward osmosis module: Hydrodynamics, fouling behaviour and cleaning strategy. Desalination 404, 249-258 (2017).

37. Kook, S. et al. Forward osmosis membranes under null-pressure condition: do hydraulic and osmotic pressures have identical nature? Environ. Sci. Technol. 52, 3556-3566 (2018).

38. Shibuya, M. et al. Effects of operating conditions and membrane structures on the performance of hollow fiber forward osmosis membranes in pressure assisted osmosis. Desalination 365, 381-388 (2015).

39. Oh, Y., Lee, S., Elimelech, M., Lee, S. \& Hong, S. Effect of hydraulic pressure and membrane orientation on water flux and reverse solute flux in pressure assisted osmosis. J. Membr. Sci. 465, 159-166 (2014).

\section{ACKNOWLEDGEMENTS}

This research was supported by the Development program to Minimizing of Climate Change Impact Technology through the National Research Foundation of Korea (NRF), funded by the Korean government (Ministry of Science and ICT(MSIT)) (No. 2020M3H5A1081109).

\section{AUTHOR CONTRIBUTIONS}

For this submission, S.-J.I. and A.J. suggested the energy-saving desalination concept and S.-J.I. and S.J. designed and performed the experiments. S.-J.I., S.J., and A.J. evaluated the economic process and prepared the manuscript. All authors discussed the experimental and economic results and have read the manuscript.

\section{COMPETING INTERESTS}

The authors declare no competing interests.

\section{ADDITIONAL INFORMATION}

Supplementary information The online version contains supplementary material available at https://doi.org/10.1038/s41545-021-00143-0. 
Correspondence and requests for materials should be addressed to A. Jang

Reprints and permission information is available at http://www.nature.com/ reprints

Publisher's note Springer Nature remains neutral with regard to jurisdictional claims in published maps and institutional affiliations.

Open Access This article is licensed under a Creative Commons Attribution 4.0 International License, which permits use, sharing, adaptation, distribution and reproduction in any medium or format, as long as you give appropriate credit to the original author(s) and the source, provide a link to the Creative Commons license, and indicate if changes were made. The images or other third party material in this article are included in the article's Creative Commons license, unless indicated otherwise in a credit line to the material. If material is not included in the article's Creative Commons license and your intended use is not permitted by statutory regulation or exceeds the permitted use, you will need to obtain permission directly from the copyright holder. To view a copy of this license, visit http://creativecommons. org/licenses/by/4.0/.

(c) The Author(s) 2021 